\title{
Caracterização da imunogenicidade das proteínas recombinantes Virb9, Virb10 e fator termo instável de Elongação de Peptídeos de Anaplasma marginale em camundongos
}

\section{Characterization of the immunogenicity of recombinant proteins VirB9, VirB10 and Elongation Factor Tu of Anaplasma marginale in mice}

\author{
Ana Beatriz Canevari CASTELÃO ${ }^{1}$; Flábio Ribeiro de ARAÚJO²; Lenita Ramires dos SANTOS ${ }^{2}$; Carlos \\ Alberto do Nascimento RAMOS ${ }^{3}$; Carina ELISEI ${ }^{3}$; Grácia Maria Soares ROSINHA ${ }^{2}$; Cleber Oliveira \\ SOARES $^{2}$ \\ ${ }^{1}$ Aluna da Programa de Pós-Graduação em Ciência Animal, Faculdade de Medicina Veterinária e Zootecnia da Universidade \\ Federal de Mato Grosso do Sul, Campo Grande-MS, Brasil. \\ ${ }^{2}$ Embrapa Gado de Corte, Campo Grande-MS, Brasil. \\ ${ }^{3}$ Bolsista DTI-CNPq.
}

\begin{abstract}
Resumo
Considerando as limitações dos atuais métodos de controle contra a anaplasmose bovina, o desenvolvimento de uma vacina efetiva se faz necessário. A partir do advento da análise genômica e proteômica, novas proteínas de membrana de Anaplasma marginale foram identificadas como possíveis candidatas a componentes de uma vacina, tais como, VirB9, VirB10 e Fator Termo Instavél de Elongação de Peptídeos (EF-Tu). Embora estas proteínas ainda não estejam bem caracterizadas na membrana de $A$. marginale, a produção destas na forma recombinante (rVirB 9, rVirB10 e rEF-Tu) tem sido realizada, mas as mesmas ainda não foram exploradas em formulações vacinais. Neste trabalho, avaliou-se o uso de rVirB9, rVirB10 e rEF-Tu emulsionadas em adjuvante Montanide em camundongos. Nas condições testadas, verificou-se a indução de forte resposta imune humoral com a produção de IgG1 e IgG2a, sendo que as proporções dos níveis de produção destas subclasses indicam predomínio de IgG1. Entretanto, esplenócitos de animais, que foram injetados com rVirB9 ou rVirB10, produziram interferon-gama acima do limite de detecção do ensaio após estimulação in vitro, sinalizando assim resposta celular específica. Assim, novas avaliações serão realizadas com a finalidade de modular o perfil de resposta imune obtido em bovinos e avaliar a proteção contra A. marginale.
\end{abstract}

Palavras-chave: Anaplasma marginale. Proteínas recombinantes. Resposta imune. Vacina. Camundongos.

\begin{abstract}
Considering the limitations of current methods of anaplasmosis control, the development of a more effective vaccine is required. Previous studies, using proteomic and genomic approaches, have identified new membrane proteins in Anaplasma marginale that may be vaccine candidates. These include VirB9, VirB10 and elongation factor-Tu (EF$\mathrm{Tu}$ ). Although the role of these proteins in the membrane of $A$. marginale has not been properly characterized, production of the recombinant proteins $\mathrm{rVirB}$, rVirB10, and $\mathrm{rEF}$-Tu has been achieved. However, these recombinant proteins have not yet been exploited in vaccine formulations. The present study describes the use of rVirB9, rVirB10 and rEF-Tu, emulsificated in adjuvant Montanide, in mice. A strong humoral immune response was induced under these conditions, with both IgG1 and IgG2a production. The IgG2a/IgG1 ratios revealed a predominance of IgG1. However, splenocytes of the animals that received rVirB9 or rVirB10 produced high levels of gamma interferon after in vitro stimulation, indicating a specific cellular immune response to these proteins. Therefore, further studies are required to adjust the profile of the immune response in order to perform tests of protection against $A$. marginale in cattle.
\end{abstract}

Keywords: Anaplasma marginale. Recombinant proteins. Immune response. Vaccine. Mice.

Correspondência para:

Ana Beatriz Canevari Castelão

Embrapa - Centro Nacional de Pesquisa em Gado de Corte

Av. Radio Maia, 830, Vila Popular - Campo Grande, MS

CEP: $79.106-550$
Telefone: +55 (67) 3368-2085 Fax: +55 (67) 3368-2150

e-mail: anabia_85@yahoo.com.br.

Recebido: 04/11/2011

Aprovado: 28/09/2012 


\section{Introdução}

A anaplasmose bovina é uma doença hemolítica causada pela riquétsia intraeritrocítica Anaplasma marginale, ${ }^{1}$ a qual é transmitida principalmente por carrapatos ixodídeos ${ }^{2}$. Essa doença ocorre principalmente em países de regiões com clima tropical e subtropical, ocasionando importantes perdas econômicas na pecuária de corte e de leite. Os sinais clínicos dessa enfermidade incluem febre, perda de peso, anemia, aborto e letargia, e ocasionalmente pode ocorrer morte, principalmente em animais acima de dois anos ${ }^{1,3}$. Os animais que sobrevivem à fase aguda da anaplasmose tornam-se persistentemente infectados, apresentando baixas riquetsemias cíclicas, não detectáveis microscopicamente $\left(\begin{array}{lll}10^{4} & \text { a } & 10^{6}\end{array}\right.$ eritrócitos infectados/mililitro de sangue), servindo então como reservatórios naturais de $A$. marginale ${ }^{4}$.

O controle da anaplasmose pode ser realizado por diferentes técnicas, entre elas, redução da população dos vetores e quimioprofilaxia. Entretanto, a forma mais econômica e efetiva para controle desta enfermidade tem sido a vacinação ${ }^{1}$. Contudo, os métodos tradicionais de imunização, oriundos de eritrócitos infectados, apresentam diversas limitações, como efeitos adversos em algumas categorias de animais, sensibilização de vacas contra grupos sanguíneos e consequente isoeritrólise neonatal em bezerros e possibilidade de veiculação de agentes patogênicos ${ }^{5}$. A busca por uma vacina que proteja os bovinos contra a doença, sem os inconvenientes das vacinas atuais, é o grande objetivo das pesquisas com subunidades de A. marginale.

As proteínas de membrana dos corpúsculos iniciais de A. marginale são foco das pesquisas voltadas para o desenvolvimento de novas vacinas contra anaplasmose. Isso ocorre principalmente porque essas proteínas estão expostas na superfície da riquétsia, sendo facilmente acessíveis ao sistema imunológico do hospedeiro, algumas delas desempenham im- portantes funções para a sobrevivência do parasito, tais como aderência e invasão dos eritrócitos do hospedeiro e transporte de nutrientes ${ }^{6}$. As primeiras proteínas de membrana de $A$. marginale purificadas e avaliadas como imunógenos, as proteínas principais de superfície (MSPs), não foram capazes de promover, em suas formas recombinantes, proteção similar àquela obtida com o uso de corpúsculos de inclusão tampouco com o uso de preparações de membrana externa de A. marginale ${ }^{7}$.

Com o advento da análise genômica e, quase que simultaneamente, proteômica de A. marginale, um novo leque de proteínas de membrana e/ou associadas à membrana da riquétsia foi identificado ${ }^{8,9,10}$. Estudos iniciais foram realizados apontando algumas proteínas como alvo em potencial ${ }^{11,12}$. Assim, o objetivo deste trabalho foi verificar a capacidade imunogênica de rVirB9, rVirB10 e rEF-Tu de $A$. marginale emulsionadas em adjuvante Montanide, em camundongos BALB/c (animal experimental de fácil manipulação, reprodutível e econômico), para avaliar a utilização dessas proteínas recombinantes como possíveis candidatas a componentes de uma vacina contra anaplasmose em bovinos.

\section{Material e Método}

A produção das proteínas recombinantes VirB9, VirB10 e EF-Tu foi realizada conforme descrito em Araújo et al. ${ }^{11}$. Brevemente, Escherichia coli Rosetta foi transformada com os plasmídeos pET47b-virb9, pET47b-virb10 e pET47b-ef-tu respectivamente e induzidas com Isopropyl $\beta$-D-1thiogalactopyranoside (IPTG). As proteínas rVirB9 e rEF-Tu foram purificadas por cromatografia de afinidade em coluna agarose níquel (HisTrap, GE HealthCare) e a proteína rVirB10 foi purificada por eletroeluição em gel de dodecil sulfato de sódio (SDSPAGE). Verificou-se a pureza das proteínas obtidas por eletroforese em SDS-PAGE, corado com azul 
brilhante de Coomassie. As proteínas recombinantes foram quantificadas por meio do método Lowry et al. ${ }^{13}$. A avaliação da antigenicidade das proteínas recombinantes foi realizada por meio de Western Blot, utilizando anticorpos específicos da espécie bovina, conforme realizado anteriormente por Araújo et al. ${ }^{11}$ As proteínas foram esterilizadas por irradiação antes de serem utilizadas.

Foram utilizados camundongos BALB/c, fêmeas, com idade entre seis e oito semanas. Os animais foram mantidos no biotério da Embrapa Gado de Corte, sob condições adequadas de temperatura e umidade e receberam alimentação e água ad libitum. O uso de animais experimentais neste trabalho foi aprovado pelo Comitê de Ética em Pesquisa da Universidade Católica Dom Bosco (Protocolo n. 035/2009A). Os animais foram separados aleatoriamente em cinco grupos de 8 animais, denominados: Salina, Montanide, rVirB9/Montanide, rVirB10/Montanide e rEF-Tu/Montanide. Os grupos Salina e Montanide representam os grupos controle do experimento, os quais foram injetados com solução salina $0,9 \%$ e Montanide ISA 70M VG (Seppic), respectivamente. Os demais grupos foram injetados com $30 \mu \mathrm{g}$ de cada proteína recombinante emulsionada ao adjuvante. O protocolo de imunização adotado consistiu em três aplicações subcutâneas, de volume de $200 \mu \mathrm{L} /$ dose, com intervalos de 21 dias. Foram realizadas duas coletas de sangue dos animais, a primeira antes do início da experimentação e outra 10 dias após a última injeção, obtendo-se então soro (pré e pósimune, respectivamente), os quais foram utilizados posteriormente para a realização de ensaios de imunoadsorção enzimática (ELISA) e Western blot.

A resposta imune humoral foi avaliada por meio de ELISA indireto (padronizados previamente para determinação das concentrações ótimas de antígenos, diluições de soro e conjugado por titulação cruzada), utilizando as proteínas rVirB9, rVirB10 e rEF-Tu, previamente solubilizadas em $2 \%$ de SDS ${ }^{14}$.
Para tanto, placas de 96 poços (Costar 3590) foram adsorvidas com 30 ng/poço de rVirB9, rVirB10 ou rEF-Tu diluídas em tampão carbonato-bicarbonato, pH 9,6 (100 mL/poço) e incubadas por uma noite a $4^{\circ} \mathrm{C}$. As concentrações de uso foram determinadas previamente. As placas foram bloqueadas com PBS com $0,05 \%$ de tween 20 (PBST) com 10\% de leite desnatado, por 1 hora a $37^{\circ} \mathrm{C}$. Todas as amostras foram analisadas em duplicatas a 1:200 ou em diluição seriada (determinação de títulos) e incubadas por 1 hora a $37^{\circ} \mathrm{C}$. Para a avaliação da produção de IgG total, o conjugado anti-IgG de camundongo com peroxidase (Sigma) foi diluído 1:10.000 e para a avaliação das subclasses foram utilizados os anticorpos biotinilados anti-IgG1 e anti-IgG2a (BD Pharmingen) diluídos a 1:500 seguido de incubação com estreptoavidina conjugada a peroxidase (R\&D Systems). As reações enzimáticas foram reveladas com TMB peroxidase (Sigma), durante 12 minutos e interrompidas com $50 \mu \mathrm{L} /$ poço de $\mathrm{H}_{2} \mathrm{SO}_{4}(2,5 \mathrm{~N})$. As densidades ópticas foram determinadas por espectrometria em leitor de ELISA com filtro de $450 \mathrm{~nm}$. A linha de corte foi determinada com base em em Frey, Di Canzio e Zurakowski ${ }^{15}$. Os níveis de produção de IgG, IgG1 e IgG2a foram determinados após diluição seriada e obtenção dos títulos finais, os quais estão representados pela recíproca da maior diluição com resultado positivo (igual ou superior à linha de corte).

Após 15 dias da última injeção, os camundongos foram eutanasiados por deslocamento cervical e os baços foram removidos assepticamente. Suspensões celulares de esplenócitos foram preparadas para cada animal em meio de cultura RPMI suplementado com $10 \%$ de soro fetalbovino, $2 \mathrm{mM} 1$-glutamina, penicilina $(100 \mathrm{U} / \mathrm{mL})$, estreptomicina $(100 \mu \mathrm{g} / \mathrm{mL})$, e $50 \mathrm{mM}$ 2-ME (Sigma Immunochemicals). Os eritrócitos foram removidos por lise com água destilada e os esplenócitos obtidos foram então adicionados em placas de 24 poços a $2 \times 10^{6} /$ poço e cultivados com $10 \mu \mathrm{g} / \mathrm{mL}$ rVirB9, rVirB10, rEF-Tu Lopez et al. ${ }^{12}$ ou 
meio de cultura por 48 horas a $37^{\circ} \mathrm{C}$, em atmosfera úmida com $5 \%$ de $\mathrm{CO}_{2}$. Concanavalina $\mathrm{A}$ foi usada na concentração de $2,5 \mu \mathrm{g} / \mathrm{mL}$ como controle positivo de estimulação de linfócitos. Após o período de incubação, os sobrenadantes das culturas foram coletados, centrifugados a $400 \mathrm{xg}$ por 10 minutos a $4^{\circ} \mathrm{C}$ para a remoção de células, e armazenados a $-70^{\circ} \mathrm{C}$. As condições de obtenção e cultivo das células foram previamente estabelecidas. A detecção/quantificação de IFN-g foi realizada utilizando um sistema de ELISA de captura comercialmente disponível (R\&D Systems), seguindo-se as instruções do fabricante.

Para comparação da produção de anticorpos entre os grupos (valores de densidade óptica) e produção de IFN-g, foi aplicado teste não-paramétrico de Kruskal-Wallis, seguido de pós-teste de comparação múltipla de Dunn's. Para comparação das médias geométricas de subclasses de IgG, foi utilizado teste não-paramétrico de Mann-Whitney.

\section{Resultados}

Os valores de densidade óptica dos ELISAs indiretos, contra cada uma das proteínas recombinantes, obtidos dos grupos controles negativos (Salina e Montanide) foram utilizados para cálculo da linha de corte (rVirB9 0,103; rVirB10 0,138; rEF-Tu 0,068). Todos os camundongos injetados com cada uma das proteínas recombinantes emulsionadas em adjuvante Montanide produziram anticorpos específicos do tipo IgG (Figura 1). Para cada um dos grupos foi estabelecido média \pm desvio-padrão com os valores de densidade óptica obtidos, sendo 1,679 $\pm 0,443$ para rVirB9 (Figura 1A), 1,670 0,238 para rVirB10 (Figura 1B) e 0,989 $\pm 0,538$ para EF-Tu (Figura 1C). A comparação entre as médias dos valores de densidade óptica dos grupos testes em relação aos grupos controles mostrou que houve diferença estatística significativa referente à produção de anticorpos $(p<0,05)$. Essa produção de anticorpos foi caracterizada por títulos elevados (média geométrica dos valores da recíproca da diluição final): rVirB9 802.671, rVirB10 561.653 e rEF-Tu 23.319. A comparação estatística destes valores indicou que as proteínas rVirB9 e rVirB10 desencadearam uma produção mais intensa de anticorpos em relação à proteína rEF-Tu $(\mathrm{p}<0,05)$. O resultado do Western blot, realizado com o pool das amostras de cada grupo, confirmou a identificação específica de cada uma das proteínas recombinantes (dados não mostrados).

Em análise subsequente, a produção das subclasses de IgG foi avaliada. Soros obtidos antes do início das injeções foram utilizados como controles negativos e para a determinação da linha de corte (rVirB9 IgG1 0,050, IgG2a 0,048; rVirB10 IgG1 0,187, IgG2a 0,194; rEF-Tu IgG1 0,229, IgG2a 0,105). Amostras obtidas dez dias após a última injeção de rVirB9, rVirB10 ou rEF-Tu apresentaram valores de densidade óptica acima da linha de corte estabelecida para cada um dos ensaios. Deste modo, a produção de IgG1 e IgG2a foi induzida em todos os grupos testados (Figura 2). Pela análise estatística revelou-se que esta produção foi significativa em relação aos controles $(p<0,05)$. A proporção da produção de $\operatorname{IgG} 2 \mathrm{a} / \operatorname{IgG} 1$ foi analisada com base nos valores de média geométrica da recíproca dos títulos finais que foram determinados para cada uma das proteínas. Assim, os níveis de IgG1 foram superiores aos níveis encontrados para IgG2a $(p<0,05)$, sendo esta proporção nos valores de: rVirB9 0,57, rVirB10 0,6396 e rEF-Tu 0,239, ou seja, todos os valores estando abaixo de 1.

A produção de IFN-g por células estimuladas in vitro com as proteínas recombinantes de $A$. marginale foi mensurada em sobrenadantes de culturas de esplenócitos. Houve produção de IFN-g, acima do limite de detecção do ensaio (>30 pg/mL), em 100\% dos animais do grupo injetado com rVirB10 e 50\% dos animais do grupo injetado com rVirB9 após estimulação específica (Figura 3). Essa produção (rVirB10 353.8 \pm 27.8; rVirB9 170,7 $\pm 251,4$ pg/mL) foi estatisticamente significante quando comparada com 

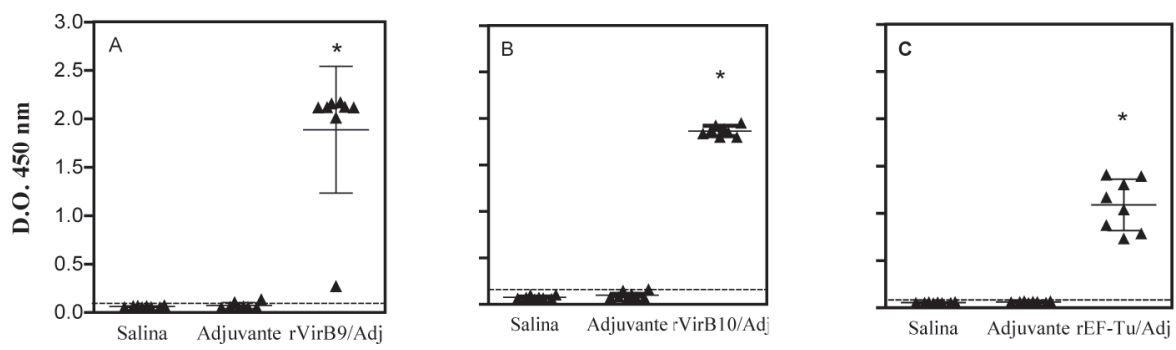

Figura 1 - Produção de anticorpos IgG total. Camundongos BALB/c foram injetados com Salina, Adjuvante Montanide ou proteínas recombinantes de Anaplasma marginale emulsionadas em adjuvante. Os resultados de ELISA indireto contra rVirB9 (A), rVirB10 (B), rEF-Tu (C) estão apresentados como valores de densidade ótica. As barras representam as médias aritméticas com desvios-padrão de cada um dos grupos e as linhas tracejadas os valores da linha de corte. Os dados apresentados são representativos de três experimentos. *Significância estatística entre grupos testes e seus respectivos controles $(\mathrm{p}<0,05)$
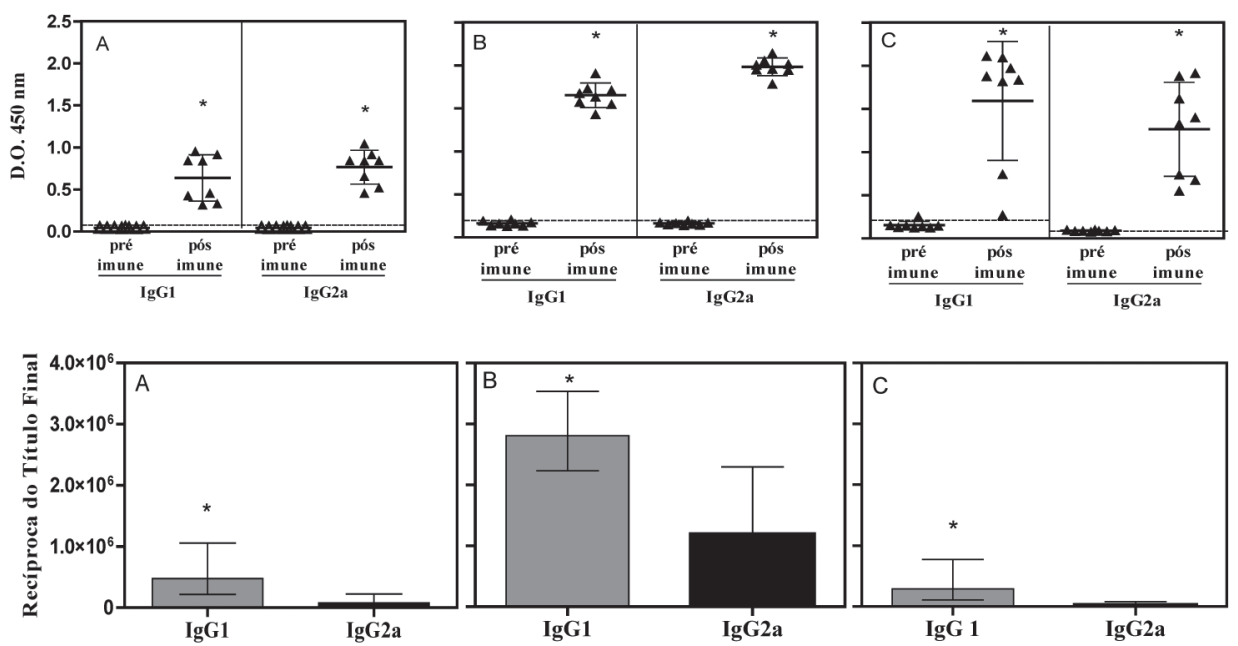

Figura 2 - Produção de anticorpos das subclasses IgG1 e IgG2a. Camundongos BALB/c foram injetados com Salina, adjuvante Montanide ou proteínas recombinantes de Anaplasma marginale emulsionadas em adjuvante. Nos gráficos superiores estão representados os resultados de ELISA Indireto contra rVirB9 (A), rVirB10 (A), rEF-Tu (C). As barras representam as médias aritméticas com desviospadrão e as linhas tracejadas indicam a linha de corte de cada um dos ensaios. ${ }^{\star}$ Significância estatística entre amostras pós e pré-imunes $(p<0,05)$. Nos gráficos inferiores estão demonstrados os valores correspondentes à recíproca da diluição dos títulos finais obtidos para cada subclasse a partir de ELISA Indireto contra rVirB9 (A), rVirB10 (B), rEF-Tu (C). *Significância estatística entre IgG1 e IgG2a $(\mathrm{p}<0,05)$. Os dados apresentados são representativos de três experimentos

os controles $(p<0,05)$. Nas condições avaliadas, células

dos animais do grupo teste rEF-Tu não produziram

IFN-g em níveis detectáveis quando estimuladas in vitro, ainda que tenha ocorrido produção no controle positivo do ensaio (dados não mostrados).

\section{Discussão}

A produção das proteínas recombinantes VirB9, VirB10 e EF-Tu têm sido realizada por diversos grupos de pesquisa ${ }^{11,12,16,17}$. VirB9 e VirB10 são proteínas do sistema de secreção do tipo IV (TFSS), 

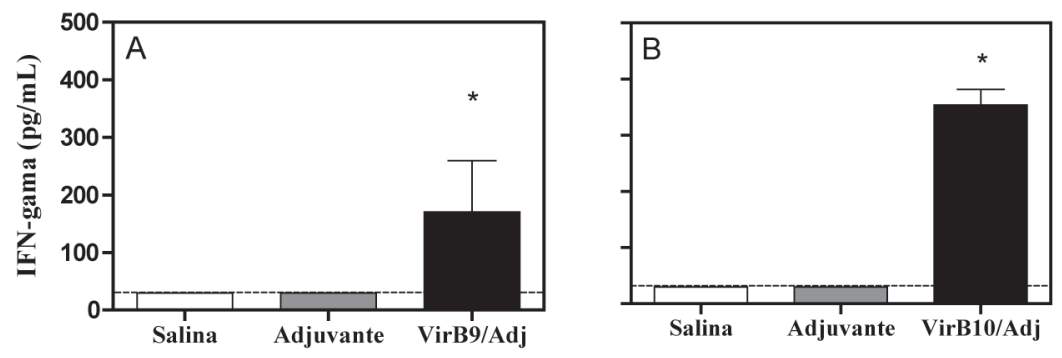

Figura 3 - Produção de interferon-gama após estimulação in vitro. Esplenócitos de camundongos BALB/c foram obtidos após a última injeção de Salina, adjuvante Montanide e rVirB9 ou rVirB10 emulsionadas em adjuvante e cultivados com rVirB9 (A) e rVirB10 (B) $(10 \mu \mathrm{g} / \mathrm{mL})$ por $48 \mathrm{~h}$ a $37^{\circ} \mathrm{C}$. Os sobrenadantes foram analisados por ELISA de captura para detecção de IFN-gama. Os resultados foram expressos em média \pm erro padrão para cada grupo. A linha tracejada indica o limite de detecção do ensaio $(30 \mathrm{pg} / \mathrm{mL})$. ${ }^{\star}$ Significância estatística entre os grupos teste e seus controles $(\mathrm{p}<0,05)$

o qual promove a secreção ou transferência de macromoléculas, proteínas ou complexos de proteína-DNA de uma célula para outra, funções estas importantes para a sobrevivência e virulência de bactérias gram negativas ${ }^{18}$. EF-Tu, embora esteja envolvida na fase de elongação da síntese proteica intracitoplasmática ${ }^{19}$, também está associada à membrana celular, sugerindo que esta proteína pode desempenhar papel importante como fator de adesão às células hospedeiras ${ }^{20}$. Além destas características, de fato, há indicações de que VirB9, VirB10 e EF-Tu sejam componentes da fração protetora de membrana externa de $A$. marginale ${ }^{9}$ e ativem o sistema imune ${ }^{11,12}$.

O mecanismo de resposta imune contra a infecção por A. marginale em bovinos ainda não foi totalmente elucidado, mas há evidências de que esta resposta seja mediada principalmente por linfócitos T CD4+, que produzem IFN-g, ativando macrófagos e estimulando linfócitos $\mathrm{B}$ a produzirem anticorpos da subclasse $\operatorname{IgG} 2 \mathrm{a}^{7,21}$. A presença isolada de anticorpos não é capaz de combater a riquétsia, fazendo-se necessária a ação conjunta da resposta imune humoral e celular ${ }^{22}$. De fato, a opsonização, fagocitose e morte dos microorganismos, mediada pelos anticorpos IgG2a e macrófagos ativados, parecem ser a peça fundamental para o controle desta riquétsia em bovinos ${ }^{7}$. As primeiras avaliações antigênicas relacionadas a VirB9, VirB10 e EF-Tu de A. marginale apresentaram-se compatíveis ao modelo acima descrito. Anticorpos IgG2a específicos reconheceram tais proteínas, em suas formas recombinantes, como demonstrado pelo uso de soro de bovinos naturalmente e experimentalmente infectados, assim como de animais imunizados com corpúsculo de membrana externa de $A$. marginale ${ }^{11,12}$. Lopez et al. ${ }^{12}$ também demonstraram a capacidade de indução de resposta celular, pela proliferação de linfócitos T e produção de IFN-g na presença destas proteínas.

Neste estudo, o uso de rVirB9, rVirB10 e rEF$\mathrm{Tu}$ em camundongos, emulsionadas em adjuvante Montanide, induziu elevados títulos de anticorpos, além de que a subclasse IgG2a específica esteve presente em todos os animais injetados com tais proteínas. Sabe-se que a utilização de adjuvantes com formulações do tipo água/óleo, como exemplificados por adjuvante completo de Freud e preparações de Montanide, atuam na modulação de resposta Th1/ Th2, favorecendo preferencialmente a indução de anticorpos e citocinas do tipo Th $1^{23,24}$. Diferentemente do esperado, nas condições utilizadas neste trabalho, uma resposta com o perfil descrito não foi encontrada, uma vez que os níveis de IgG1 foram superiores aos 
encontrados para IgG2a, indicando polarização para resposta do tipo Th2. Poucos estudos realizados com proteínas recombinantes de superfície de $A$. marginale e avaliação de adjuvantes em camundongos estão disponíveis na literatura. Avaliações com as MSPs, associadas aos adjuvantes ISCOM/ISCOMATRIX, não revelaram diferenças entre a produção de IgG1 e $\operatorname{IgG} 2 \mathrm{a}^{25}$, enquanto que a utilização de vetores plasmidiais favorece um predomínio de $\operatorname{IgG} 2 \mathrm{a}^{26}$. Vale ressaltar que estas avaliações foram realizadas pela comparação dos valores de densidade óptica, o que não necessariamente condiz com os níveis de produção.

O adjuvante Montanide ISA 70 M VG (SEPPIC) é um adjuvante desenvolvido particularmente para uso em bovinos e pequenos ruminantes (informações do fabricante). A capacidade de induzir forte resposta imune humoral e resposta celular do tipo Th1 para antígenos associados foi a característica de eleição para a inclusão deste adjuvante neste estudo ${ }^{23,27,28}$. O mecanismo de ação proposto para este adjuvante baseia-se principalmente na formação de depósito, propiciando lenta liberação do antígeno no sítio de injeção, além da capacidade de potencialização da resposta imune pelo desenvolvimento de processo inflamatório ${ }^{23,27}$. Salientamos que não realizamos experimentos independentes para avaliar o grau de participação do adjuvante em relação aos antígenos testados. Comumente, antígenos administrados sem o uso de adjuvantes resultam em respostas imune mais fracas ou mesmo em ausência de resposta ${ }^{24,27,28}$, o que define por base a necessidade de inclusão de adjuvantes em formulações vacinais, como visto na prática médica e veterinária. Um método simples foi utilizado para preparação da emulsão, garantindo a obtenção de diâmetros adequados para as partículas do adjuvante e mantendo a estabilidade da formulação vacinal $^{29}$.

É bem caracterizado que, no modelo murino, citocinas produzidas por células $\mathrm{T}$ ativadas induzem a troca de diferentes subclasses de anticorpos IgG, sendo que a resposta Th1 é caracterizada pela produção de IFN-g e indução de anticorpos IgG2a ${ }^{30}$. Neste estudo, toda a população de camundongos injetados com a proteína rVirB10 e metade da população de camundongos injetados com a proteína rVirB9 foram capazes de desenvolver uma resposta imune celular com produção de IFN-g, desencadeando assim a produção de IgG2a. No entanto, para o uso da proteína rEF-Tu não houve equivalência entre a produção de IgG2a e a detecção de IFN-g. Essa discrepância pode ser explicada por diversos fatores. Lopez et al. ${ }^{12} \mathrm{em}$ seu estudo com proteínas recombinantes do TFSS avaliadas in vitro contra células de bovinos imunizados com membrana externa de $A$. marginale também encontra produção de IgG2a específica sem produção de IFN-g contra rCTP, justificando este fato à uma baixa frequência de células $\mathrm{T}$ específicas respondedoras. Outras possibilidades envolvem questões técnicas relacionadas a estabilidade da proteína, otimização de cinética e dose-resposta para obtenção de valores acima do limite de detecção e utilização de métodos mais sensíveis para a mensuração desta citocina.

Alternativamente, a utilização de uma associação de proteínas de membrana externa de $A$. marginale poderia ser adotada com a finalidade de modular o perfil de resposta imune obtido. Estudos recentes sugerem que VirB9 e VirB10 interagem na membrana externa e são reconhecidas em conjunto, de modo a ativar células B e células T simultaneamente ${ }^{17}$. Assim, novos experimentos a partir de rVirB9 e rVirB10 associadas serão conduzidos.

\section{Conclusões}

A partir dos dados deste experimento é possível concluir que nas condições testadas rVirB9, rVirB10 e rEF-Tu são capazes de induzir forte resposta imune humoral, produzindo elevados títulos de IgG1 e 
IgG2a, embora os níveis de IgG1 estejam acima dos níveis encontrados para IgG2a, além de que rVirB10 e rVirB9 também são capazes de induzir produção de IFN-g após estimulação in vitro. Ainda se faz necessário o ajuste de algumas condições para que a resposta imune obtida possua características semelhantes às encontradas na proteção contra esta enfermidade, bem como a reprodução de novos experimentos no modelo bovino.

\section{Referências}

1. KOCAN, K. M.; DE LA FUENTE, J.; GUGLIELMONE, A. A.; MELENDEZ, R. D. Antigens and alternatives for control of Anaplasma marginale infection in cattle. Clinical Microbiology Review, v. 16, n. 4, p. 698-712, 2003.

2. RIKIHISA, Y. Mechanisms to create a safe haven by members of the family Anaplasmataceae. Annals of the New York Academy of Sciences, New York, v. 990, p. 548-555, 2003.

3. AJAYI, S. A.; WILSON, A. J.; CAMPBELL, R. S. F. Experimental bovine anaplasmosis: Clinico-pathological and nutritional studies. Research in Veterinary Science, v. 25, n. 1, p. 76-81, 1978.

4. KIESER, S. T.; ERIKS, I. S.; PALMER, G. H. Cyclic rickettsemia during persistent Anaplasma marginale infection of cattle. Infection and Immunity, Washington DC, v. 58, n. 4, p. 1117-1119, 1990.

5. KESSLER, R. H.; SCHENK, M. A. M. Tristeza parasitária dos bovinos (TPB): conceito, etiologia, transmissão, epidemiologia, diagnóstico e controle. In: KESSLER, R. H.; SCHENK, M. A. M. (Ed.). Carrapato, tristeza parasitária e tripanossomose dos bovinos. Campo Grande: Embrapa Gado de Corte, 1998. p. 47-67.

6. DE LA FUENTE, J.; GARCIA-GARCIA, J. C.; BLOUIN, E. F.; KOCAN, K. M. Differential adhesion of major surface proteins $1 \mathrm{a}$ and $1 \mathrm{~b}$ of the ehrlichial cattle pathogen Anaplasma marginale to bovine erythrocytes and tick cells. International Journal of Parasitology, v. 31, n. 2, p. 145-153, 2001.

7. BROWN, W. C.; SHKAP, V.; ZHU, D.; MCGUIRE, T. C.; TUO, W.; MCELWAIN, T. F.; PALMER, G. H. CD4+ T-lymphocyte and immunoglobulin G2 responses in calves immunized with Anaplasma marginale outer membranes and protected against homologous challenge. Infection and Immunity, v. 66, n. 11, p. 5406-5413, 1998.

8. BRAYTON, K. A.; KAPPMEYER, L. S.; HERNDON, D. R.; DARK, M. J.; TIBBALS, D. L.; PALMER, G. H.; MCGUIRE, T. C.; KNOWLES, D. P. JR. Complete genome sequencing of Anaplasma marginale reveals that the surface is skewed to two superfamilies of outer membrane proteins. Proceedings of the National Academy of Sciences of the United States of America, v. 102, n. 3, p. 844-849, 2005.

9. LOPEZ, J. E.; SIEMS, W. F.; PALMER, G. H.; BRAYTON, K. A.; MCGUIRE, T. C.; NORIMINE, J.; BROWN, W. C. Identification of novel antigenic proteins in a complex Anaplasma marginale outer membrane immunogen by mass spectrometry and genomic mapping. Infection and Immunity, v. 73, n. 12, p. 8109-8118, 2005.

10.DARK, M. J.; AL-KHEDERY, B.; BARBET, A. F. Multistrain genome analysis identifies candidate vaccine antigens of Anaplasma marginale. Vaccine, v. 29, n. 31, p. 4923-4932, 2011.

\section{Agradecimentos}

A Aline Ariano da Silva e Nádia Caroline Sobrinho

Gaúna pelo auxílio experimental, Renato Henrique Marçal pelo suporte laboratorial, Instituto Oswaldo Cruz (Salvador, BA) e Instituto de Pesquisa Energéticas e Nucleares pela irradiação das proteínas.

Suporte financeiro: FUNDECT, Embrapa Gado de Corte.

11.ARAÚJO, F. R.; COSTA, C. M.; RAMOS, C. A. N.; FARIAS, T. A.; SOUZA, I. I. F.; MELO, E.; ELISEI, C.; ROSINHA, G. M. S.; SOARES, C. O.; FRAGOSO, S. P.; FONSECA, A. H. IgG and IgG2 antibodies from cattle naturally infected with Anaplasma marginale recognize the recombinant vaccine candidate antigens VirB9, VirB10, and elongation factor-Tu. Memórias do Instituto Oswaldo Cruz, v. 103, n. 2, p. 186-190, 2008.

12.LOPEZ, J. E.; PALMER, G. H.; BRAYTON, K. A.; DARK, M. J.; LEACH, S. E.; BROWN, W. C. Immunogenicity of Anaplasma marginale type IV secretion system proteins in a protective outer membrane vaccine. Infection and Immunity, v. 75, n. 2, p. 2333-2342, 2007.

13.LOWRY, O. H.; ROSEBROUGH, N. J.; FARR, A. L.; RANDALL, R. J. Protein measurement with the Folin phenol reagent. Journal of Biology Chemistry, v. 193, n. 1, p. 265$275,1951$.

14.LECHTZIER, V.; HUTORAN, M.; LEVY, T.; KOTLER, M.; BRENNER, T.; STEINITZ, M. Sodium dodecyl sulphate-treated proteins as ligands in ELISA. Journal of Immunological Methods, v. 270, n. 1, p. 19-26, 2002.

15. FREY, A.; DI CANZIO, J.; ZURAKOWSKI, D. A statistically defined endpoint titer determination method for immunoassays. Journal of Imunological Methods, v. 221, n. 1-2, p. 35-41, 1998.

16. VIDOTTO, M. C.; VENÂNCIO, E. J.; VIDOTTO, O. Cloning, sequencing and antigenic caracterization of rVirB9 of Anaplasma marginale isolate from Paraná State, Brazil. Genetics and Molecular Research, v. 7, n. 2, p. 460-466, 2008.

17.MORSE, K.; NORIMINE, J.; PALMER, G. H.; SUTTEN, E. L.; BASZLER, T. V.; BROWN, W. C. Association and evidence for linked recognition of type IV secretion system proteins VirB91, VirB9-2, and VirB10 in Anaplasma marginale. Infection and Immunity, v. 80, n. 1, p. 215-227, 2012.

18. CHRISTIE, P.J.; VOGEL, J.P. Bacterial typeIV secretion: Conjugation systems adapted to deliver effector molecules to host cells. Trends in Microbiology, Cambridge, v. 8, n. 8, p. 354-360, 2000.

19. JONÁK J. Bacterial elongation factors EF-Tu, their mutants, chimeric forms, and domains: Isolation and purification. Journal of Chromatography. B, Analytical Technologies in the Biomedical and Life Sciences, v. 849, n. 1-2, p. 141-153, 2007.

20.GRANATO, D.; BERGONZELLI, G. E.; PRIDMORE, R. D.; MARVIN, L.; ROUVET, M.; CORTHE'SY-THEULAZ, I. E. Cell Surface-associated elongation factor Tu Mediates the attachment of Lactobacillus johnsonii NCC533 (La1) to human intestinal cells and mucins. Infection and Immunity, v. 72, n. 4, p. 2.160-2.169, 2004. 
21.ESTES, D. M.; ClOSSER, N. M.; ALLEN, G. K. IFNstimulates IgG2 production from bovine B cells costimulated with anti- $\mu$ and mitogen. Cellular Immunology, v. 154, n. 1, p. 287-295, 1994.

22.BROWN, W. C.; PALMER, G. H.; LEWIN, H. A.; MCGUIRE. T. C. CD4+ T lymphocytes from calves immunized with Anaplasma marginale Major Surface Protein 1 (MSP1); a heteromeric complex of MSP1a and MSP1b; preferentially recognize the MSP1a carboxyl terminus that is conserved among strains. Infection and Immunity, v. 69, n. 11, p. 6853$6862,2001$.

23.REED, S. G.; BERTHOLET, S.; COLER, R. N.; FRIEDE, M. New horizons in adjuvants for vaccine development. Trends in Immunology, v. 30, n. 1, p. 23-32, 2008.

24. HABJANEC, L.; HALASSY, B.; TOMASIC, J. Immunomodulatory activity of novel adjuvant formulations based on Montanide ISA oil-based adjuvants and peptidoglycan monomer. International Immunopharmacology, v. 8, p. 717-724, 2008.

25.KAWASAKI, P. M.; KANO, F. S.; TAMEKUNI, K.; GARCIA. J. L.; MARANA, E. R. M.; VIDOTTO, O.; VIDOTTO, M. C. Immune response of $\mathrm{BALB} / \mathrm{c}$ mouse immunized with recombinant MSPs proteins of Anaplasma marginale binding to immunostimulant complex (ISCOM). Research in Veterinary Science, v. 83, n. 3, p. 347-354, 2007.

26.KANO, F. S.; TAMEKUNI, K.; COELHO, A. L.; GARCIA, J.
L.; VIDOTTO, O.; ITANO, E. N.; VIDOTTO, M. C. Induced immune response of DNA vaccine encoding an association MSP1a, MSP1b, and MSP5 antigens of Anaplasma marginale. Vaccine, v. 26, p. 3522-3527, 2008.

27.MUTISO, J. M.; MACHARIA, J. C.; TARACHA, E.; WAFULA, K.; RIKOI, H.; GICHERU, M. M. Safety and skin delayedtype hypersensitivity response in vervet monkeys immunized with Leishmania donovani sonicate antigen delivered with adjuvants. Revista do Instituto de Medicina Tropical de São Paulo, v. 54, n. 1, p. 37-41, 2012.

28.LANGELLOTI, C. A.; PAPPALARDO, J. S.; QUATTROCCHI, V.; MONGINI, C.; ZAMORANO, P. Induction of specific cytotoxic activity for bovine herpesvirus-1 by DNA immunization with different adjuvants. Antiviral Research, v. 90, n. 3, p. 134-142, 2011.

29. MILES, A. P.; MCCLELLAN, H. A.; RAUSCH, K. M.; ZHU, D.; WHITMORE, M. D.; SINGH, S.; MARTIN, L. B.; WU, Y.; GIERSING, B. K.; STOWERS, A. W.; LONG, C. A.; SAUL, A. Montanide ISA 720 vaccines: quality control of emulsions, stability of formulated antigens, and comparative immunogenicity of vaccine formulations. Vaccine, v. 23, n. 19, p. 2530-2539, 2005.

30.SNAPPER, C. M.; PAUL, W. E. Interferon-gamma and B cell stimulatory factor-1 reciprocally regulate Ig isotype production. Science, v. 236, n. 4804, p. 944-947, 1987. 